\title{
Natural Killer Cell Activation by Weissella cibaria JW15 Isolated from Kimchi
}

\section{Eun Young Oh, Sang-Myeong Lee*}

Laboratory of Veterinary Virology, College of Veterinary Medicine, Chungbuk National University, Cheongju 28644, Republic of Korea

\section{Corresponding}

Sang-Myeong Lee, D.V.M., Ph.D.

Laboratory of Veterinary Virology, College

of Veterinary Medicine, Chungbuk National

University, Cheongju 28644, Republic of

Korea

Phone : +82-43-261-3356

Fax : +82-43-267-3150

E-mail : smlee@cbnu.ac.kr

Received : April 14, 2021

Revised : April 27, 2021

Accepted : April 28, 2021

No potential conflict of interest relevant to this article was reported.

Copyright (C) 2021 Journal of Bacteriology and Virology

(C) This is an Open Access article distributed under the terms of the Creative Commons Attribution Non-Commercial

License

(http://creativecommons.org/

license/by-nc/3.0/).
Natural killer (NK) cells are innate immune cells with the capacity to eliminate virus-infected and cancer cells. Therefore, enhancing NK cell activity remains a promising strategy to control viral infection and cancer development. Recent studies highlighted the immunostimulatory effect of lactic acid bacteria (LAB), especially via activation of NK cells. Among LAB, Weissella cibaria JW15, isolated from kimchi, activated splenocytes and enhanced immune responses, but whether JW15 enhanced NK cell activity was unclear. In this study, we investigated if JW15 affects NK cell activity and a possible role of exopolysaccharides (EPS) produced by JW15 in immune-stimulatory activity. Splenocytes or NK cells isolated from mice were treated with live JW15 or EPS, and then evaluated for cell surface levels of activation markers, intracellular levels of granzyme B and perforin, cytokine production, including IFN- $\gamma$, and cytotoxicity against tumor cells. Our results revealed that JW15 induced the activation of NK cells, as shown by increased NK cell cytotoxicity activity, as well as increased activation markers and IFN- $\gamma$ production. In addition, EPS activated NK cells and splenocytes, leading to the secretion of various cytokines. Furthermore, oral administration of live JW15 increased NK cell cytotoxicity. Taken together, our findings suggest JW15 as a promising probiotic candidate strain with the immune-enhancing potential to prevent or treat viral infection and cancer.

Key Words: Lactic acid bacteria, Weissella cibaria JW15, Natural killer cell, Exopolysaccharide

\section{INTRODUCTION}

Probiotics are defined as live microorganisms that confer beneficial health effects to the host (1-3). Most probiotic microorganisms are lactic acid bacteria (LAB), such as Lactobacillus sp., Leuconostoc sp., Lactococcus sp., Enterococcus sp., and Weissella sp. (4). The effects of probiotics on animals and humans have been studied intensively, and many reports suggest the use of probiotics as preventive or therapeutic agents for various pathological conditions. For instance, some probiotics have been shown to improve hypertension (5) and diarrhea induced by antibiotics or rotavirus $(6,7)$, prevent cancer $(8,9)$, reduce cholesterol levels $(10,11)$, or alleviate intestinal problems, such as irritable bowel syndrome and inflammatory bowel disease $(12,13)$. With the increased prevalence of various diseases related to the immune response, much interest is focused on the prevention or treatment of diseases through the immunomodulatory effects of $L A B(14)$. 
$L A B$ are gram-positive, lactic acid-producing, non-spore-forming cocci or rod-shaped bacteria, usually found in fermented foods and dairy products $(15,16)$. Weissella sp. were classified as LAB in $1993(17)$. Bacteria in this genus are often found in the gastrointestinal tract of humans or animals, as well as in fermented foods, such as fermented sausages $(18,19)$. Weissella cibaria has been isolated from Korean fermented food, various other foods, and human and animal feces (20). Several studies have investigated the probiotic potential of the Weissella genus and some functional properties relevant to their use as probiotics, particularly their ability to enhance immune responses by inducing the generation of inflammatory mediators $(20,21)$. Notably, W. cibaria produces weissellicin, an antibacterial substance $(21)$, with an anticancer effect in colorectal cancer (22) and an antiviral effect against avian influenza virus (23). In addition, the $W$. cibaria strain JW15 (JW15) isolated from kimchi, a Korean traditional fermented food, possesses immune-stimulatory activity and induces pro-inflammatory cytokines, such as interleukin (IL)-1 $\beta$ and tumor necrosis factor-alpha (TNF- $\alpha$ ), as well as nitric oxide, in macrophages (24). These findings suggest that $W$. cibaria could be developed as a probiotic to enhance the immune responses to infectious diseases or cancers.

Natural killer (NK) cells are granulocytes with an important role in initiating the innate immune response (25). NK cells recognize and kill tumor and virus-infected cells without prior specific sensitization (26). NK cells exhibit cytotoxic effects by recognizing target cells based on the absence of major histocompatibility complex class I (MHC I) molecules $(27,28)$. To evade immune detection and elimination, viruses often down-regulate these molecules, and cancer cells express low levels of MHC I molecules. However, both are preferentially targeted and removed by NK cells (29). NK cell cytotoxicity is mediated by the binding of death receptors or the release of cytolytic granules stored in the cytoplasm upon target cell recognition, or both $(30,31)$. The granules contain perforin and granzymes, pore-forming protein and serine proteases, respectively. Released perforin forms pores in the target cell membrane, leading to the entry of granzymes into the cells, which, in turn, initiate apoptosis (32). NK cells also produce type II interferon (IFN), IFN- $\gamma$, which enhances NK cell activity by positive feedback loop and activate macrophages $(33,34)$. IFN- $\gamma$ plays an important role in both adaptive and innate immunity. Therefore, it is plausible to suggest that enhancing NK cell activity is an attractive strategy to prevent or treat viral infection and cancer.

Various plant molecules or extracts can activate NK cells $(35,36)$. In addition, some LAB strains activate NK cell activity in vitro and in vivo. For example, Lactobacillus delbrueckii ssp. bulgaricus OLL1073R-1 increased NK cell activity and antiviral activity against the influenza virus $(37,38)$. Bifidobacterium lactis HN019 enhanced tumoricidal activity of NK cells (39). However, it is not clear whether the immunostimulatory effects of JW15 are mediated by NK cell activation because previous studies used a mixture of lymphocytes or macrophages (24). To resolve this dilemma, the present study was designed to evaluate immunoregulatory effect of JW15 on murine NK cell activation and cytotoxicity in vitro and in vivo.

\section{MATERIALS AND METHODS}

\section{Bacterial culture}

JW15 (KACC 91811P), isolated from kimchi, and Lactobacillus rhamnosus GG (LGG, ATCC 53103) were cultured in Lactobacilli de Man-Rogosa-Sharpe (MRS) broth (BD Biosciences, San Jose, CA, USA) at $200 \mathrm{rpm}, 37^{\circ} \mathrm{C}$ for 5.5 and $14.5 \mathrm{~h}$, respectively. Bacterial cells were collected by centrifugation at 1,500 $\times g$ for $10 \mathrm{~min}$. The resultant cell pellet was washed twice with sterile phosphate-buffered saline (PBS, pH 7.2). Viable bacterial cells were counted on MRS agar plates.

\section{Mice}

$\mathrm{BALB} / \mathrm{C}$ and C57BL/6 male mice were purchased from Samtako, Inc. (Osan-si, Republic of Korea) and were maintained at $22-24^{\circ} \mathrm{C}$ and $45-55 \%$ relative humidity under a $12 \mathrm{~h}$ light/dark cycle. Mice were fed normal chow. All mice experiments were performed according to the guidelines from the Animal Care and Use Committee (ACUC) of Jeonbuk National University (Approval number: CBNU 2019-014). 


\section{Splenocytes preparation}

Spleens were isolated from $B A L B / c$ mice, and single-cell suspensions were prepared by passing through a $40-\mu m$ cell strainer (BD Falcon, Bedford, MA, USA). Cells were washed with PBS and treated with red blood cell lysis buffer (eBioscience, USA). Then, cells were resuspended in Roswell Park Memorial Institute (RPMI) 1640 medium (GE Healthcare Life Sciences, USA) supplemented with $2.05 \mathrm{mM}$ L-glutamine, 10\% (v/v) heat-inactivated fetal bovine serum (FBS; Capricorn Scientific, Germany) and $1 \%(\mathrm{v} / \mathrm{v})$ penicillin-streptomycin $(10,000 \mathrm{U} / \mathrm{mL}$ penicillin, 10,000 $\mathrm{kg} / \mathrm{mL}$ streptomycin; Gibco, USA).

\section{Isolation of NK cells}

NK cells were isolated from the splenocytes of BALB/c mice using the MagniSort Mouse NK cell Enrichment Kit (eBioscience), in accordance with the manufacturer's instructions. NK cells were cultured in RPMI 1640 medium (GE Healthcare Life Sciences) supplemented with $2.05 \mathrm{mM}$ L-glutamine, 10\% (v/v) heat-inactivated FBS (Capricorn Scientific) and $1 \%(\mathrm{v} / \mathrm{v})$ penicillin-streptomycin $(10,000 \mathrm{U} / \mathrm{mL}$ penicillin, 10,000 $\mathrm{mg} / \mathrm{mL}$ streptomycin; Gibco).

\section{NK cell cytotoxicity assay}

Splenoctyes or NK cells were seeded in a 96-well plate and co-cultured with Yac-1 cells (NK sensitive-target cell) stained with carboxyfluorescein succinimidyl ester (CFSE; eBioscience) at an effector cell:target cell ratio of 10:1. After 4 h, cells were stained with propidium iodide (PI) staining solution (eBioscience) and dead cells (CFSE and $\mathrm{Pl}^{+}$) analyzed using a $\mathrm{BD}$ Acurri C6 flow cytometer (BD Biosciences).

\section{Flow cytometry analysis of NK cell activation markers}

Cells were collected and washed with FACS buffer ( $3 \%$ HI-FBS and $0.02 \%$ sodium azide in PBS). Then, single-cell suspensions were stained with anti-mouse CD3 (PerCP/Cy5.5, BioLegend, USA), CD49b (APC, BioLegend), CD69 (FITC, eBioscience), or NKG2D/CD314 (PE, BioLegend) antibodies in FACS buffer and incubated for 30 min on ice in the dark, followed by flow cytometry analysis. For intracellular cytokine staining, cells were restimulated with PMA/ionomycin (eBioscience) and brefeldin A (eBioscience) and incubated at $37^{\circ} \mathrm{C}$ for $4 \mathrm{~h}$. After cell surface staining, cells were incubated with IC Fixation Buffer (eBioscience) for 30 min and washed using $1 \mathrm{X}$ Permeabilization Buffer (eBioscience). Cells were stained with anti-mouse granzyme B (FITC, eBioscience), perforin (PE, eBioscience), or IFN- $\gamma$ (FITC, BioLegend) antibodies in 1X Permeabilization Buffer for $30 \mathrm{~min}$. Cells were resuspended in FACS buffer, and the results were detected and analyzed by flow cytometry.

\section{Enzyme-linked immunosorbent assay (ELISA)}

Cell culture supernatants were harvested from EPS treatment experiments and used to determine cytokine levels using enzyme-linked immunosorbent assay (ELISA) kits according to the manufacturer's instructions. The ELISA kits used were mouse TNF- $\alpha$, IL-12 (BioLegend), IL-6, IL-17, and IFN- $\gamma$ (eBioscience).

\section{Isolation and purification of EPS from JW15 culture}

EPS was isolated from JW15, as described in previous study (40), Briefly, single colony was inoculated in sucrose broth (1\% tryptone, $0.5 \%$ yeast extract, $0.5 \%$ dipotassium phosphate, $0.5 \%$ diammonium citrate, $5 \%$ sucrose, $\mathrm{pH} 7.0$ ) and incubated at $37^{\circ} \mathrm{C}$ in a shaking incubator for $48 \mathrm{~h}$. Afterward, the sucrose broth was added with $4 \%(\mathrm{w} / \mathrm{v})$ trichloroacetic acid (Sigma-Aldrich, St. Louis, MO, USA) and incubated at $4^{\circ} \mathrm{C}$ for $2 \mathrm{~h}$. After centrifugation $(10,000 \times \mathrm{g}$, $4^{\circ} \mathrm{C}, 25 \mathrm{~min}$ ), the supernatant was collected and precipitated with two volumes of cold $95 \%$ ethanol at $4^{\circ} \mathrm{C}$ overnight, 
then centrifugated $\left(10,000 \times g, 4^{\circ} \mathrm{C}, 25 \mathrm{~min}\right)$. The resultant pellet was resuspended in triple distilled water. It was named as the crude EPS solution and treated with $50 \mu \mathrm{g} / \mathrm{mL}$ of DNase I (Sigma-Aldrich) and RNase A (Thermo Fisher Scientific Inc., Waltham, MA, USA) at $37^{\circ} \mathrm{C}$ for $6 \mathrm{~h}$, followed by $200 \mu \mathrm{g} / \mathrm{mL}$ of proteinase $\mathrm{K}$ (GeneAll, Seoul, Republic of Korea) under the same condition. The solution was mixed with two volumes of chilled $95 \%$ ethanol and precipitated at $4^{\circ} \mathrm{C}$ overnight. The EPS pellet was collected by centrifugation $\left(10,000 \times g, 4^{\circ} \mathrm{C}, 25 \mathrm{~min}\right)$, washed with $70 \%$ ethanol, and re-centrifuged. After the supernatant was removed, the purified EPS pellet was dissolved in triple distilled water and lyophilized.

\section{Oral administration of JW15 to mice}

Eight-week-old C57BL/6 male mice were divided into three groups and administered $100 \mu \mathrm{L}$ of saline, live JW15, or live LGG $\left(1.0 \times 10^{9}\right)$ once daily via oral gavage. After 14 days, all mice were sacrificed, and the spleens were collected for NK cell activity evaluation.

\section{Statistical analysis}

All experimental data are expressed as means \pm standard error of the means (SEM) of triplicate samples. Statistical analysis involved unpaired $t$-tests or a one-way ANOVA at a significance level of $p<0.05$ using GraphPad PRISM ${ }^{\circledR}$ (GraphPad Software, Inc., USA).

\section{RESULTS}

\section{JW15 activates the cytotoxic activity of splenocytes by activating NK cells}

To evaluate the effect of live JW15 on NK cells activity, splenocytes were treated with JW15 at 1:0.1, 1:1, or 1:5 ratio for 20-24 h and tested for cytotoxicity against Yac-1 cells, as target cells. LGG is a well-known probiotic bacterium that was used in this study to compare with JW15. As shown in Fig. 1A, the cytotoxic activity was significantly increased as the ratio of live JW15 to splenocytes was increased $(p<0.01, p<0.001)$. A similar effect on cytotoxicity was observed for LGG $(p<0.05, p<0.01)$. Although these results suggest that live JW15 stimulates the cytotoxicity of immune cells included in splenocytes, it is unclear whether enhanced cytotoxicity of splenocytes by JW15 treatment is mediated by NK cell activation. To determine whether JW15 is able to activate NK cells, IFN-8 production and cell surface expression of activation markers and granules were measured by flow cytometry. When splenocytes were gated on NK cells (CD3-

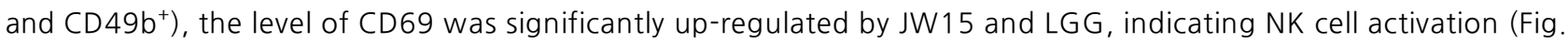
1B). Cell surface expression of NKG2D, an activating cell surface receptor, was not affected by JW15 stimulation but was down-regulated by LGG (Fig. 1C). Next, we analyzed the intracellular levels of perforin and granzyme, both major components of cytolytic granules of NK cells. JW15 treatment of splenocytes at 1:5 ratio tended to increase granzyme B, albeit without statistical significance, whereas significantly higher perforin levels were detected in JW15-treated NK cells (Fig. 1D,E). Activated NK cells produce IFN- $\gamma$. When the frequency of IFN- $\gamma$-producing cells was evaluated, it was found that JW15 induced IFN- - -producing NK cells at higher frequencies compared to LGG, especially at lower ratios (Fig. 1F). These results indicate that JW15 might increase cytotoxicity against Yac-1 cells via NK cell activation.

\section{JW15 directly activates NK cells}

Although JW15-treated splenocytes showed increased NK cell activation and cytotoxicity, it was still unclear if JW15 acted directly on NK cells. To assess the direct effect of JW15 on NK cells, we first examined whether JW15 affects tumor cell 
killing by NK cell-mediated cytotoxicity in vitro. NK cells were purified from splenocytes and stimulated with either JW15 or LGG to analyze the cytolytic activity against Yac-1 cells. Compared to untreated cells, JW15 significantly enhanced NK cell cytotoxicity against Yac-1 cells in a dose-dependent manner, unlike LGG, which did not affect the cytotoxic activity of NK cells, even at the highest ratio (Fig. 2A). Next, we examined whether JW15 up-regulated the levels of intracellular granzyme B and perforin. As shown in Fig. 2B,C, JW15-treated NK cells possessed higher levels of granzyme B and perforin in cytoplasm than the non-treated cells. By contrast, LGG treatment did not affect the intracellular levels of granzyme $B$. Similarly, JW15 augmented the frequencies of NK cells producing IFN- $\gamma$ by significant amounts, but LGG did not (Fig. 2D). Collectively, these results suggest that JW15 activates NK cells directly and enhances the cytotoxic activity against tumor cells. Contrarily, LGG acts on NK cells indirectly.

A

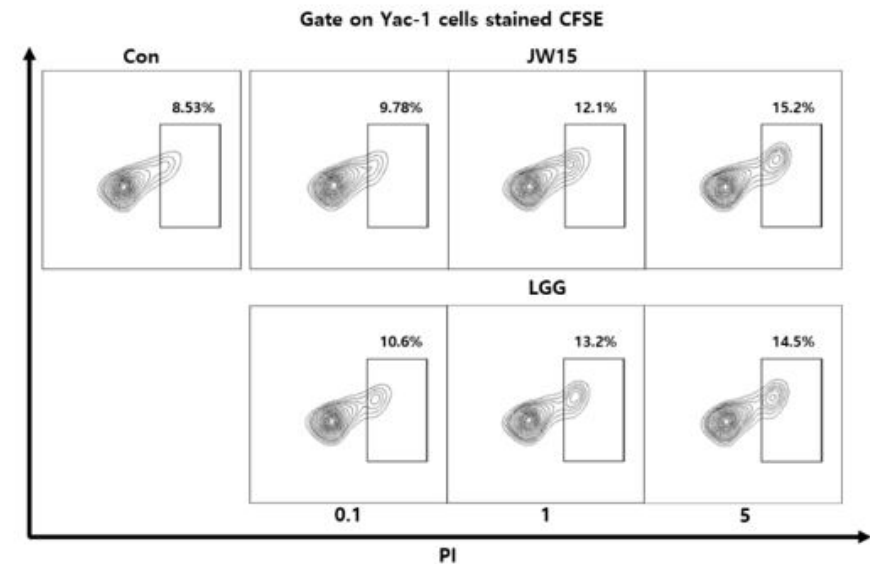

PI

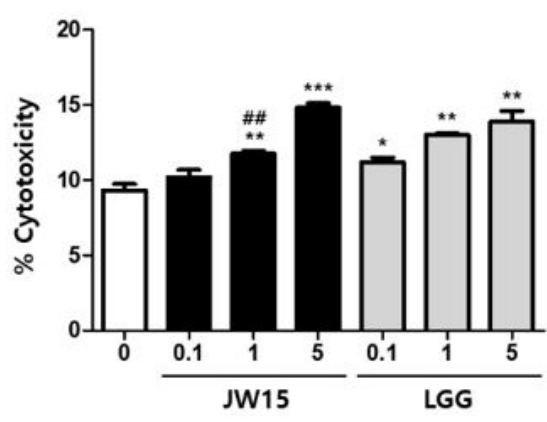

D

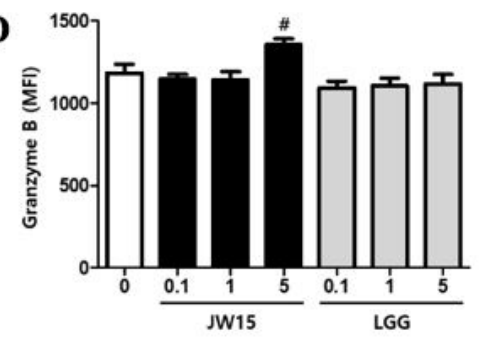

$\mathbf{E}$

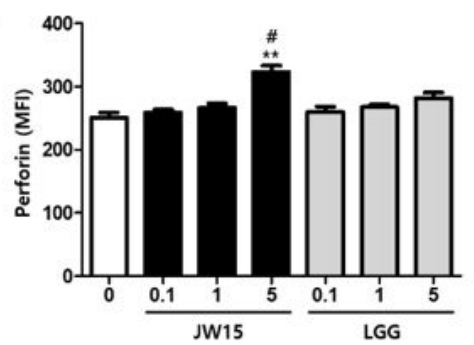

C

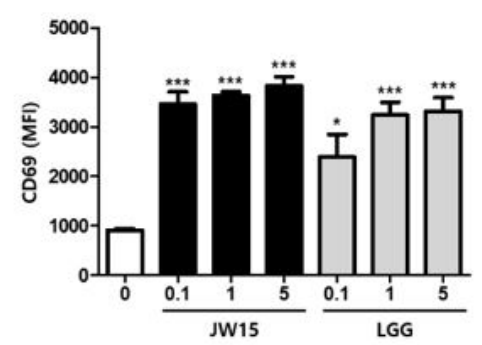

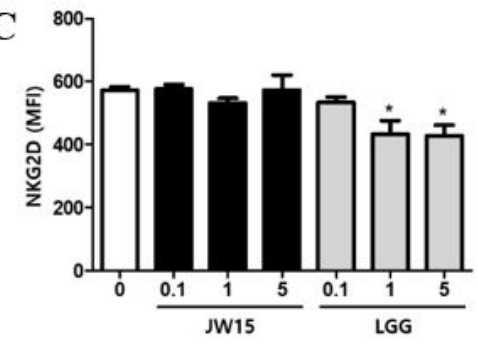

$\mathbf{F}$

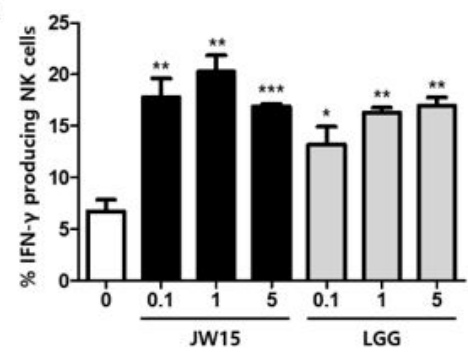

Fig. 1. Effect of JW15 on cytotoxic activity of splenocytes and NK cell activation. Splenocytes of BALB/C mice were treated with live JW15 or LGG at 1:0.1, 1:1, and 1:5 ratio for 20-24 h. (A) Cells were co-cultured with Yac-1 cells stained with CFSE at a 1:10 ratio (Yac-1 cells:splenocytes) for $4 \mathrm{~h}$. Then, cells were stained with $\mathrm{Pl}$ and detected by flow cytometry. (B-F) Splenocytes were stained with antibodies against CD3, CD49b, CD69, NKG2D, granzyme B, perforin, and IFN- $\gamma$ and detected by flow cytometry. Cells were gated on $\mathrm{CD}^{-} \mathrm{CD} 49 \mathrm{~b}^{+} \mathrm{NK}$ cells, and MFI or percentage of each staining is shown. These experiments were repeated three times independently. Results are expressed as mean \pm SEM. $* p<0.05, * \star p<0.01, * \star \star p<0.001$ compared with control group. $\# p<0.05, \# \# p<0.01$ comparison between JW15 and LGG. 
$\mathbf{A}$
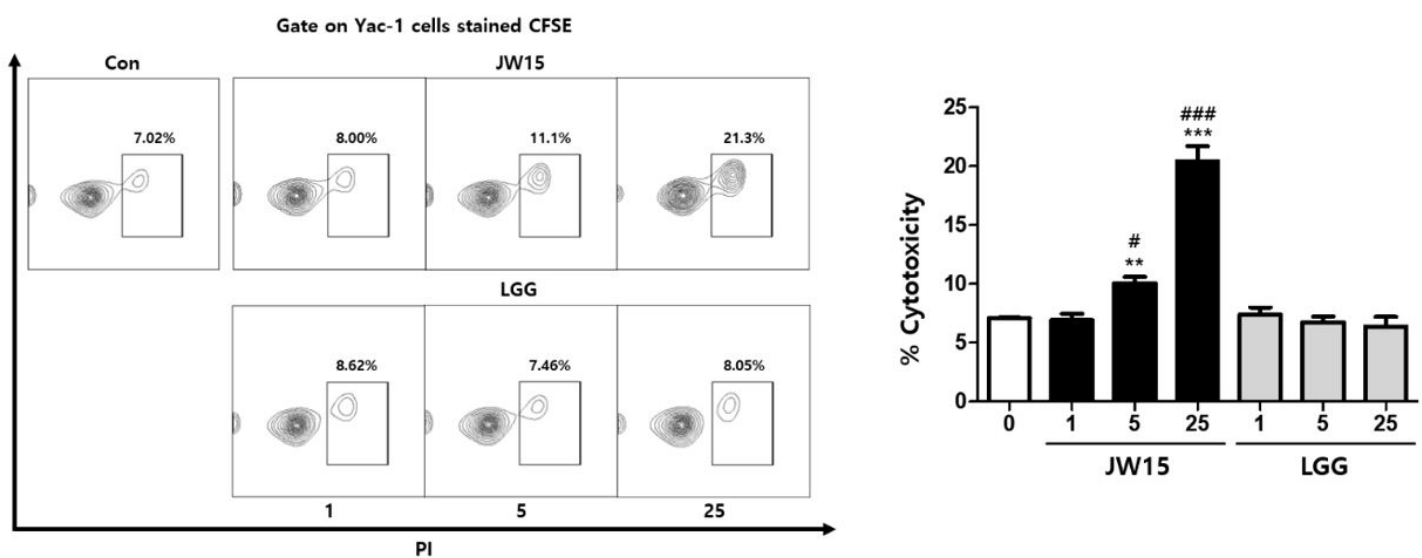

B

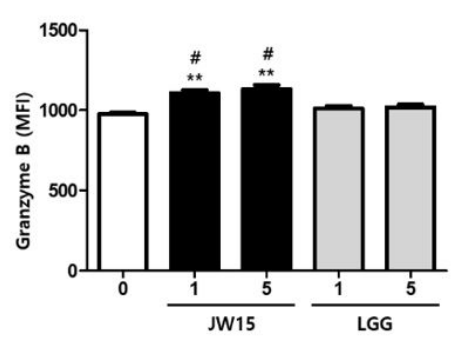

C

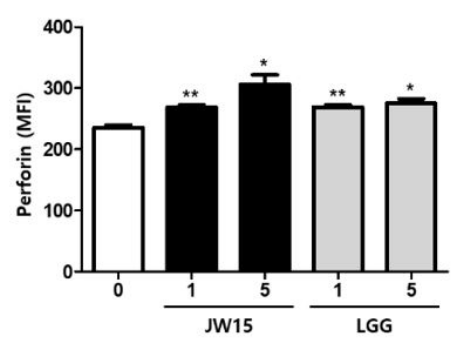

D

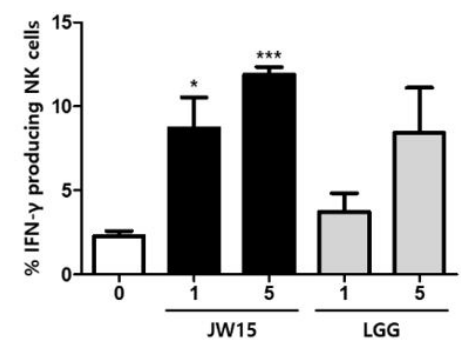

Fig. 2. Activation of NK cells by stimulation with JW15. NK cells isolated from BALB/C mice were treated with live JW15 and LGG in the presence of gentamicin $(50 \mu \mathrm{g} / \mathrm{mL}$ ). (A) After $20 \mathrm{~h}$, Yac-1 cells labeled with CFSE were co-cultured with NK cells at a 1:10 ratio for $4 \mathrm{~h}$ and stained with PI. The frequency of killed Yac-1 cells $\left(\mathrm{PI}^{+}\right.$gated on CFSE) was then detected by flow cytometry. (B-D) After 24 h, NK cells were stained with antibodies against CD3, CD49b, CD69, NKG2D, granzyme B, perforin, and IFN- $\gamma$ and detected by flow cytometry. Cells were gated on $\mathrm{CD}^{-} \mathrm{CD}_{4} \mathrm{~b}^{+} \mathrm{NK}$ cells, and MFI or percentage of each staining is shown. Data are expressed as mean \pm SEM of triplicate samples. $* p<0.05, * \star p<0.01, * \star \star p<0.001$ compared with control group. $\# p<0.05, \# \# \#<0.001$ comparison between JW15 and LGG.

\section{EPS isolated from JW15 activates NK cells indirectly}

Various mechanisms by which $L A B$ exert beneficial health effects have been proposed, and EPS was shown to mediate the immune-related function of $\operatorname{LAB}(41,42)$. Here, we investigated whether EPS isolated from JW15 culture could activate immune cells and enhance the cytolytic activity against tumor cells and whether such activity is mediated via NK cell activation. To evaluate if EPS is responsible for the immunomodulatory function of JW15, splenocytes were treated with EPS at various concentrations, and then the cell culture supernatants were analyzed for cytokine secretion. The production of pro-inflammatory cytokines, such as IL- 6 and TNF- $\alpha$, was significantly increased by EPS treatment (Fig. 3A,B). IL-12, mainly produced by dendritic cells and macrophages, was also detected at higher levels in the cell culture supernatant when cells were treated with EPS (Fig. 3C). In addition, EPS treatment up-regulated IFN- $\gamma$ and IL-17 secretion dose-dependently, and this effect was significant (Fig. 3D,E). Lipopolysaccharide (LPS) was included as a positive control and induced significant levels of cytokines, which were higher than those induced by EPS or comparable with EPS at the highest concentration, except for IL-17. These findings indicate that EPS from JW15 exerts an immunostimulatory effect and suggest that EPS might enhance the cytotoxic activity of NK cells against tumor cells. To test this idea, we performed the NK cell cytotoxicity assay using splenocytes treated with EPS as effector cells. As a result, EPS treatment potentiated the cytotoxicity of splenocytes up to $8.29 \%$ compared to the untreated control (Fig. 4A). NK cell activation by EPS was further confirmed by up-regulated expression of CD69, perforin and IFN- $\gamma$ (Fig. 4B-F). Collectively, these results provide promising evidence that EPS mediates the immune-stimulatory activity of JW15 and plays a role in the NK cell-mediated cytotoxic activity of JW15. 
A

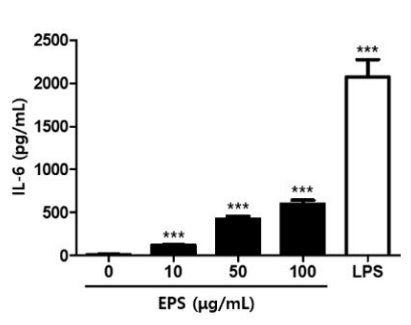

B

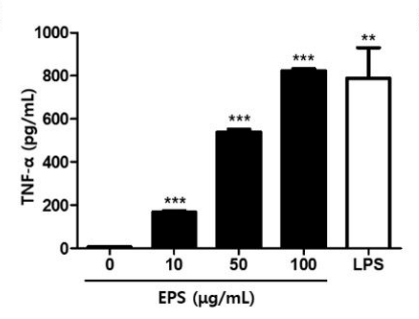

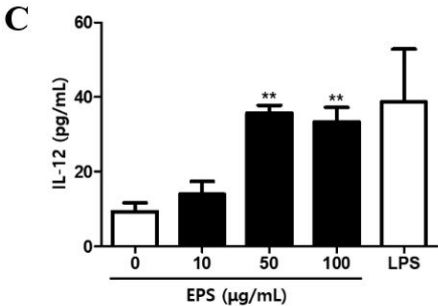

D

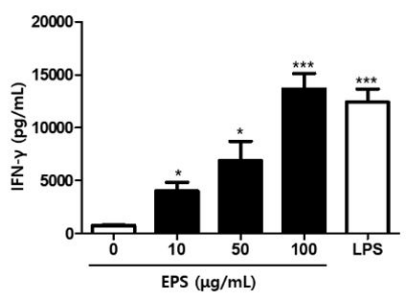

$\mathbf{E}$

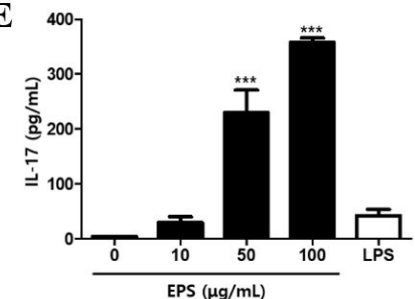

Fig. 3. Effect of EPS on cytokine secretion by splenocytes. Splenocytes were stimulated with EPS or LPS ( $200 \mathrm{ng} / \mathrm{mL})$ for $24 \mathrm{~h}$. The cell culture supernatants were harvested and used to analyze cytokines levels by ELISA kits. Data are expressed as the mean \pm SEM of triplicate samples. $* p<0.05, * * p<0.01, * * * p<0.001$ compared with control group.

A
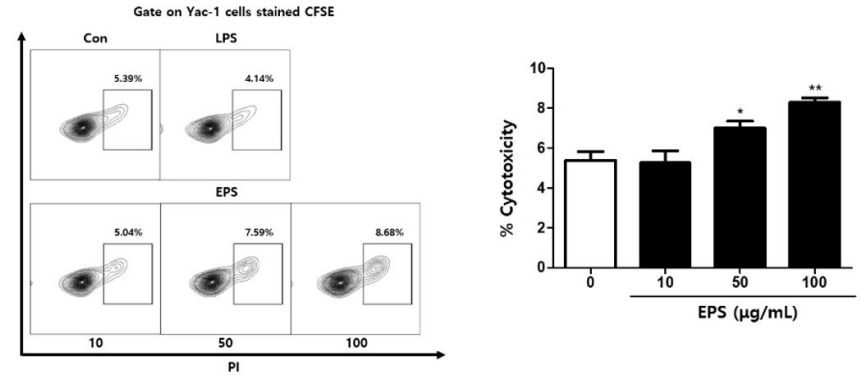

B

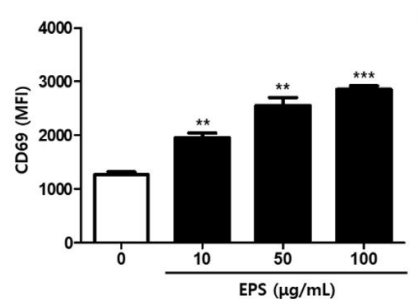

C

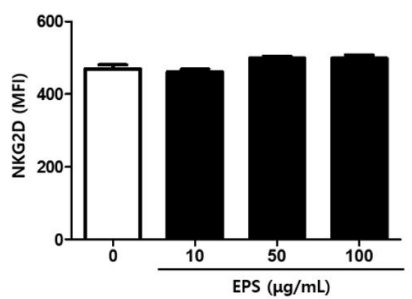

D

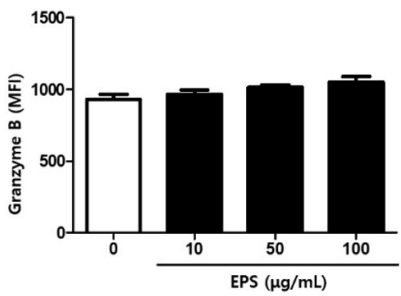

$\mathbf{E}$
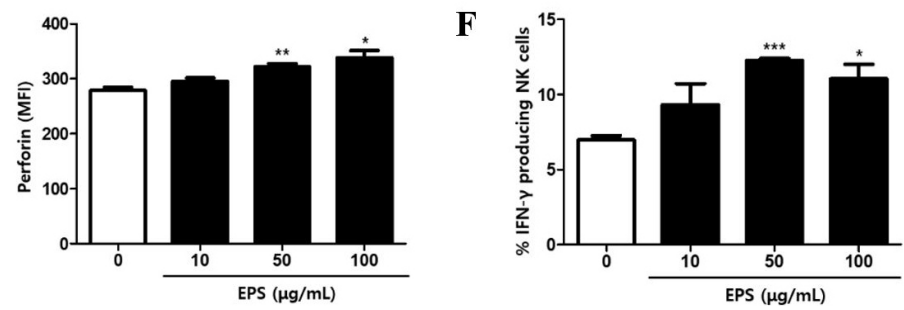

Fig. 4. Effect of EPS on NK cell activation. Splenocytes were treated with EPS at 10, 50, and $100 \mu \mathrm{g} / \mathrm{mL}$. (A) After $22 \mathrm{~h}$, these cells were co-cultured at a 5:1 ratio with CFSE-labeled Yac-1 cells for $2 \mathrm{~h}$. Then, cells were stained with PI. The frequency of killed Yac-1 cells ( $\mathrm{Pl}^{+}$gated on CFSE) was detected by flow cytometry. (B-F) After incubation for $24 \mathrm{~h}$, cells were stained with antibodies against CD3, CD49b, CD69, NKG2D, granzyme B, perforin, and IFN- $\gamma$ and detected by flow cytometry. Cells were gated on CD3-CD49b $b^{+} \mathrm{NK}$ cells, and MFI or percentage of each staining is shown. Data are expressed as the mean \pm SEM of triplicate samples. $* p<0.05, * \star p<0.01, * * \star p<0.001$ compared with control group. 
A
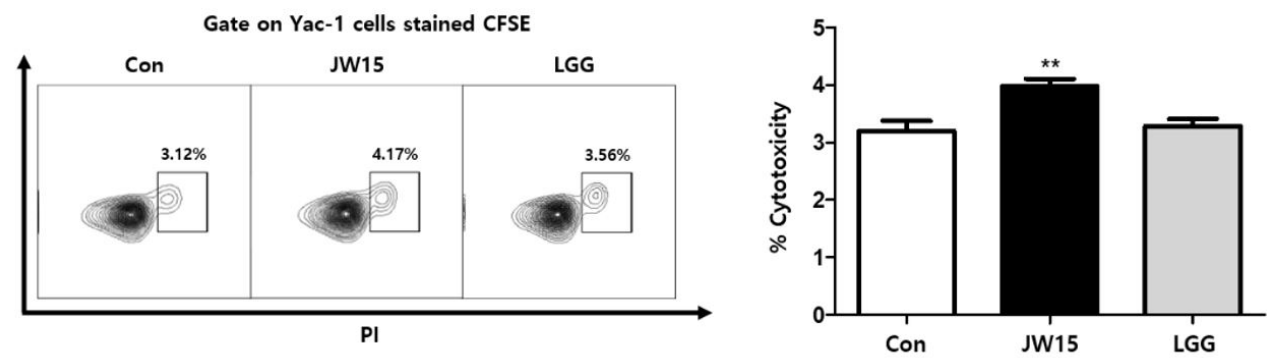

B
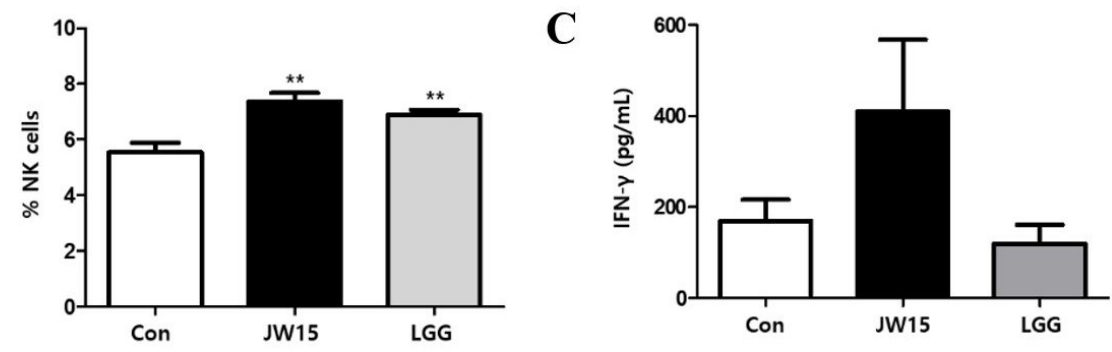

Fig. 5. Effect of oral administration of JW15 on NK cells. C57BL/6 mice were administered with JW15 or LGG daily for 14 days and then euthanized to harvest spleen. (A) A single-cell suspension of splenocytes was co-cultured with CFSE-labeled Yac-1 cells at a 10:1 ratio for $4 \mathrm{~h}$. Then, cells were stained with $\mathrm{PI}$ and analyzed by flow cytometry for $\mathrm{Pl}^{+}$gated on CFSE-stained cells as killed Yac-1 cells. (B) Splenocytes were stained for NK cells (CD3 CD49b ${ }^{+}$) and subjected to flow cytometry analysis or (C) treated with IL-2 $(20 \mathrm{ng} / \mathrm{mL})$ for $18 \mathrm{~h}$, and then secreted IFN- $\gamma$ in the supernatants was detected by ELISA. Data are expressed as the mean \pm SEM of triplicate samples. $* * p<0.01$ compared with control group.

\section{Oral administration of JW15 increases NK cell activity in mice}

According to the in vitro experiment, it is plausible that the administration of live JW15 may enhance NK cell activity. To test the effect of JW15 in vivo, mice were orally administered either with live JW15 or with LGG daily, for 14 days. Then, mice splenocytes were isolated and tested for NK cell cytotoxicity against Yac-1 cells. Unlike the administration of LGG, JW15 administration significantly enhanced the level of killed target cells (Fig. 5A). Unexpectedly, the frequency of NK cells among splenocytes was increased by both LAB species (Fig. 5B). In addition, stimulation of splenocytes with IL-2 (20 $\mathrm{ng} / \mathrm{mL}$ ) for $18 \mathrm{~h}$ showed up-regulated IFN- $\gamma$ secretion in JW15-treated mice compared to the control or LGG-treated group (Fig. 5C). However, the effect of JW15 on IFN-8 induction was not significant. Finally, our in vivo results suggest that oral administration of JW15 enhances NK cell activity in mice.

\section{DISCUSSION}

The beneficial effects of LAB on human health have been studied for many years. The immune system plays an essential role in most human diseases, including cancer, obesity, bacterial or viral infection, and cardiovascular diseases (43). Some $L A B$ species are able to stimulate or suppress both innate and acquired immune responses (44). Therefore, immuno-modulatory functions of $L A B$ have been considered as one of the most important aspects of $L A B$ on human health. Recently, NK cell activation by LAB was demonstrated by several groups and suggested as a promising strategy to control viral infection and prevent cancer $(45,46)$. Here, we provide in vitro and in vivo evidence that $W$. cibaria JW15 (isolated from kimchi, a Korean traditional fermented food) effectively activates NK cells and enhances their cytotoxic activity against tumor cells.

NK cells are well-known as sentinel cells of the innate immunity system. They represent a major component of cytotoxic lymphocytes with the ability to recognize abnormal cells, such as tumor cells and virus-infected cells, and kill those cells 
without pre-sensitization (26). In addition, NK cells also play a role in adaptive immunity (47), such as the augmentation of T cell-mediated immune responses by interacting with dendritic cells. The diverse functions and essential roles of NK cells in protective immunity, especially against viral infection and cancer, have suggested that augmenting the NK cell response could be an attractive strategy to develop prophylactics or therapeutics for those diseases. We demonstrated that JW15 acted as an effective NK cell activator and increased the cytotoxic response of NK cells against a tumor cell line in vitro. It was found that JW15 directly activated NK cells and increased intracellular cytolytic molecules, such as perforin and granzyme B, as well as IFN- $\gamma$, a potent immunostimulatory cytokine. Yamane et al. demonstrated that a mixture of kefir-isolated $L A B$ increased the tumor cell cytotoxicity of an NK cell line in vitro (48), providing evidence for the direct effect of LAB on NK cells. We further confirmed the stimulatory effect of JW15 on NK cells in vivo. Daily administration of live JW15 via oral gavage enhanced the cytotoxic effect of NK cells on cancer cells ex vivo, consistent with a previous study that showed daily consumption of JW15 enhanced NK cell activity in non-diabetic subjects (49). These findings imply that the consumption of live JW15 could help prevent tumorigenesis by increasing NK cell-mediated surveillance system. However, further animal disease model studies are necessary to confirm our finding, which was revealed in normal mice. Oral administration of $L A B$ is reported to ameliorate cyclophosphamide-induced immunosuppression by activating NK cells in mice (50). The antitumoral effect of $L A B$ treatment has also been studied in mouse model. For instance, preventive intranasal treatment of Lactobacillus caseiBL23 delayed tumor onset through a mechanism partially associated with NK cell activation and recruitment (51). Similarly, in a mouse study, L. casei Shirota delayed tumorigenesis induced by 3-methylcholanthrene (52). NK cell activation by LAB oral administration was also suggested as an effective prophylactic regimen for viral infection. LGG, L. pentosus S-PT84, L. plantarum nF1, and L. delbrueckii OLL1073R-1 enhanced host immunity via NK cell activation and protected mice from influenza A virus infection (53-56).

Many LAB species are known to produce EPS, glycan structures present outside of the bacterial cell wall. The beneficial properties of LAB-produced EPS have drawn considerable interest for their immune-modulatory effect. As mentioned above, some studies reported that the EPS produced by LAB regulates both innate and adaptive immunity, leading to health-promoting benefits (41). It is recognized that the ability of EPS to stimulate immune cells differs among LAB species or strains, possibly due to structural differences of EPS (42). Hence, the search for EPS-producing LAB strains, especially in high amounts, is of great interest. Weissella cibaria is well-known to produce copious amounts of EPS compared to other LAB (57). However, the immunostimulatory role of EPS produced by JW15 has not yet been fully studied. To address this knowledge gap, we sought to determine whether EPS produced by JW15 stimulates cytokine production in splenocytes and examine the cytotoxic activity of NK cells in vitro. The secretion of a significant amount of cytokines by splenocytes treated with EPS reflected the immune-stimulatory activity of EPS, and this was further confirmed by the increased NK cell activation markers and cytotoxicity against tumor cells. In accordance with the results of a study, EPS derived from yogurt fermented with L. delbrueckii OLL1073R-1 enhanced NK cell cytotoxicity in vitro (56). Moreover, EPS isolated from L. rhamnosus KL37 and RW-9595M was shown to induce pro-inflammatory cytokines, such as TNF- $\alpha$, IL-6, and IL-12, in mouse peritoneal macrophages and, RAW 264.7 and peripheral blood mononuclear cells, respectively (58). Results of our and other groups suggest that EPS from LAB possess immunostimulatory properties and lead to proposing EPS as a new bioactive molecule with potential nutraceutical and pharmaceutical applications. However, our findings were based upon a simple in vitro study. Further studies are necessary to decipher the potential role of EPS form JW15 in an animal model that involves complex interactions among immune cells and various other cells and with the intestinal microbiome.

The present study demonstrated that live JW15 activates NK cells, important immune cells in the innate immune response, by increasing the expression of various activation markers, such as CD69 and NKG2D, and components of cytolytic granules. Additionally, we showed that EPS from JW15 enhanced the activation of NK cells. Moreover, the daily administration of live JW15 up-regulated the frequencies and cytotoxic activity of NK cells. Taken together, these findings suggest that enhancing NK cell-mediated immune responses by the consumption of live JW15 serve as a prophylactic strategy to prevent tumorigenesis and viral infection. Further studies are necessary to confirm immunostimulatory effects of JW15 and EPS in animal models of viral infection or cancer and reveal the detailed immunological and molecular mechanisms utilized by JW15 and EPS isolated from JW15. 


\section{ACKNOWLEDGEMENTS}

This work was supported by the Cooperative Research Program for Agriculture Science \& Technology Development, Rural Development Administration, Republic of Korea (Project number PJ010835).

\section{REFERENCES}

1) Ouwehand AC, Kirjavainen PV, Shortt C, Salminen S. Probiotics: mechanisms and established effects. International Dairy Journal 1999:9:43-52.

2) Schrezenmeir J, de Vrese M. Probiotics, prebiotics, and synbiotics-approaching a definition. Am J Clin Nutr 2001; 73:361s-4s.

3) Drisko JA, Giles CK, Bischoff BJ. Probiotics in health maintenance and disease prevention. Altern Med Rev 2003:8:143-55.

4) Klein G, Pack A, Bonaparte C, Reuter G. Taxonomy and physiology of probiotic lactic acid bacteria. Int J Food Microbio/1998:41:103-25.

5) Lye HS, Kuan CY, Ewe JA, Fung WY, Liong MT. The improvement of hypertension by probiotics: effects on cholesterol, diabetes, renin, and phytoestrogens. Int J Mol Sci2009;10:3755-75.

6) Marteau P, Seksik P, Jian R. Probiotics and intestinal health effects: a clinical perspective. Br J Nutr 2002;88 Suppl 1:s51-7.

7) Isolauri $E$, Juntunen $M$, Rautanen $T$, Sillanaukee $P$, Koivula $T$. A human Lactobacillus strain (Lactobacillus casei $s p$ strain GG) promotes recovery from acute diarrhea in children. Pediatrics 1991:88:90-7.

8) De Leblanc ADM, Matar C, Perdigón G. The application of probiotics in cancer. Br J Nutr 2007:98 Suppl 1:S105-10.

9) Mohammadi M. Probiotics and cancer. Journal of Biology 2013:2(4):202-9.

10) Tahri K, Grille JP, Schneider F. Bifidobacteria strain behavior toward cholesterol: coprecipitation with bile salts and assimilation. Curr Microbio/ 1996:33:187-93.

11) Lin MY, Chen TW. Reduction of cholesterol by Lactobacillus acidophilus in culture broth. J Food Drug Anal 2000;8:97-102.

12) Madden JAJ, Hunter JO. A review of the role of the gut microflora in irritable bowel syndrome and the effects of probiotics. BrJ Nutr 2002;88 Suppl 1:s67-72.

13) Shanahan F. Probiotics and inflammatory bowel disease: from fads and fantasy to facts and future. Br J Nutr 2002;88 Suppl 1:s5-9.

14) Tsai $Y T$, Cheng PC, Pan TM. The immunomodulatory effects of lactic acid bacteria for improving immune functions and benefits. App/Microbiol Biotechno/2012;96:853-62.

15) Collins MD, Gibson GR. Probiotics, prebiotics, and synbiotics: approaches for modulating the microbial ecology of the gut. Am J Clin Nutr 1999;69:1052s-7s.

16) Simon GL, Gorbach SL. Intestinal flora in health and disease. Gastroenterology 1984;86:174-93.

17) Collins MD, Samelis J, Metaxopoulos J, Wallbanks S. Taxonomic studies on some Leuconostoc-like organisms from fermented sausages: description of a new genus Weissella for the Leuconostoc paramesenteroides group of species. $J$ App/ Bacterio/ 1993;75:595-603.

18) De Bruyne K, Camu N, De Vuyst L, Vandamme P. Weissella fabaria sp. nov., from a Ghanaian cocoa fermentation. Int J Syst Evol Microbiol 2010;60:1999-2005. 
19) Padonou SW, Schillinger U, Nielsen DS, Franz CMAP, Hansen M, Hounhouigan JD, et al. Weissella beninensis sp. nov., a motile lactic acid bacterium from submerged cassava fermentations, and emended description of the genus Weissella. Int J Syst Evol Microbio/ 2010;60:2193-8.

20) Björkroth KJ, Schillinger U, Geisen R, Weiss N, Hoste B, Holzapfel WH, et al. Taxonomic study of Weissella confusa and description of Weissella cibaria sp. nov., detected in food and clinical samples. Int J Syst Evol Microbio/2002;52:141-8.

21) Kang M, Lim HS, Kim SM, Lee HC, Oh JS. Effect of Weissella cibaria on Fusobacterium nucleatum-induced interleukin-6 and interleukin-8 production in KB cells. J Bacterio/ Viro/2011:41:9-18.

22) Cha S, Ahn B, Kim J. Weissella cibaria 148-2 lactic bacteria for functional healthy effect and Makgeolli containing the same. inventors; Google Patents, assignee, 2008.

23) Rho JB, Poo H, Choi YK, Kim CJ, Sung MH. New lactic acid bacteria having its inhibitory effect on avian influenza virus infection and composition containing the same. inventors; Google Patents, assignee, 2012.

24) Ahn SB, Park HE, Lee SM, Kim SY, Shon MY, Lee WK. Characteristics and immuno-modulatory effects of Weissella cibaria JW15 isolated from Kimchi, Korea traditional fermented food, for probiotic use. Journal of Biomedical Research. 2013;14:206-11.

25) Lanier LL. NK cell recognition. Annu Rev Immuno/2005;23:225-74.

26) Herberman RB. Natural killer cells. Annu Rev Med 1986;37:347-52.

27) Ljunggren HG, Kärre K. In search of the 'missing self': MHC molecules and NK cell recognition. Immunol Today 1990;11:237-44

28) Cassidy SA, Cheent KS, Khakoo SI. Effects of Peptide on NK cell-mediated MHCI recognition. Front Immuno/2014;5:133.

29) Vivier E, Tomasello E, Baratin M, Walzer T, Ugolini S. Functions of natural killer cells. Nat Immuno/2008;9:503-10.

30) Smyth MJ, Cretney E, Kelly JM, Westwood JA, Street SEA, Yagita H, et al. Activation of NK cell cytotoxicity. Mol Immuno/2005:42:501-10

31) Biron CA, Nguyen KB, Pien GC, Cousens LP, Salazar-Mather TP. Natural killer cells in antiviral defense: function and regulation by innate cytokines. Annu Rev Immuno/ 1999;17:189-220.

32) Trapani JA, Smyth MJ. Functional significance of the perforin/granzyme cell death pathway. Nat Rev Immunol 2002:2:735-47.

33) Martín-Fontecha A, Thomsen LL, Brett S, Gerard C, Lipp M, Lanzavecchia A, et al. Induced recruitment of NK cells to lymph nodes provides IFN- $\gamma$ for $\mathrm{T}(\mathrm{H}) 1$ priming. Nat Immuno/ 2004;5:1260-5.

34) Gerosa F, Baldani-Guerra B, Nisii C, Marchesini V, Carra G, Trinchieri G. Reciprocal activating interaction between natural killer cells and dendritic cells. J Exp Med 2002;195:327-33.

35) Grudzien M, Rapak A. Effect of natural compounds on NK cell activation. J Immunol Res 2018;2018:4868417.

36) Lu CC, Hsu YJ, Chang CJ, Lin CS, Martel J, Ojcius DM, et al. Immunomodulatory properties of medicinal mushrooms: differential effects of water and ethanol extracts on NK cell-mediated cytotoxicity. Innate Immun 2016:22:522-33.

37) Makino S, Ikegami S, Kano H, Sashihara T, Sugano H, Horiuchi H, et al. Immunomodulatory effects of polysaccharides produced by Lactobacillus delbrueckii ssp. bulgaricus OLL1073R-1. J Dairy Sci 2006:89:2873-81.

38) Makino S, Ikegami S, Kume A, Horiuchi H, Sasaki H, Orii N. Reducing the risk of infection in the elderly by dietary intake of yoghurt fermented with Lactobacillus delbrueckii ssp. bulgaricus OLL1073R-1. Br J Nutr 2010;104:998-1006.

39) Gill HS, Rutherfurd KJ, Cross ML, Gopal PK. Enhancement of immunity in the elderly by dietary supplementation with the probiotic Bifidobacterium lactis HN019. Am J Clin Nutr 2001;74:833-9.

40) Bajpai VK, Majumder R, Rather IA, Kim K. Extraction, isolation and purification of exopolysaccharide from lactic acid 
bacteria using ethanol precipitation method. Bangladesh J Pharmacology 2016:11:573-6.

41) Laiño J, Villena J, Kanmani P, Kitazawa $\mathrm{H}$. Immunoregulatory effects triggered by lactic acid bacteria exopolysaccharides: new insights into molecular interactions with host cells. Microorganisms 2016:4:27.

42) Hidalgo-Cantabrana C, López P, Gueimonde M, de Los Reyes-Gavilán CG, Suárez A, Margolles A, et al. Immune modulation capability of exopolysaccharides synthesised by lactic acid bacteria and bifidobacteria. Probiotics Antimicrob Proteins 2012:4:227-37.

43) Fernández-Ruiz Icc. Immune system and cardiovascular disease. Nat Rev Cardio/2016;13:503.

44) Masood MI, Qadir MI, Shirazi JH, Khan IU. Beneficial effects of lactic acid bacteria on human beings. Crit Rev Microbio/2011;37:91-8.

45) Cheon S, Lee KW, Kim KE, Park JK, Park S, Kim CH, et al. Heat-killed Lactobacillus acidophilus La205 enhances NK cell cytotoxicity through increased granule exocytosis. Immunol Lett 2011;136:171-6.

46) Gill HS, Rutherfurd KJ, Cross ML. Dietary probiotic supplementation enhances natural killer cell activity in the elderly: an investigation of age-related immunological changes. J Clin Immuno/2001:21:264-71.

47) Moretta A, Marcenaro E, Parolini S, Ferlazzo G, Moretta L. NK cells at the interface between innate and adaptive immunity. Cell Death Differ 2008;15:226-33.

48) Yamane $T$, Sakamoto $T$, Nakagaki $T$, Nakano $Y$. Lactic acid bacteria from kefir increase cytotoxicity of natural killer cells to tumor cells. Foods 2018;7:48.

49) Lee YJ, Lee $A$, Yoo HJ, Kim M, Noh GM, Lee JH. Supplementation with the probiotic strain Weissella cibaria JW15 enhances natural killer cell activity in nondiabetic subjects. J Functional Foods 2018:48:153-8.

50) Jin SW, Lee GH, Jang MJ, Hong GE, Kim JY, Park GD, et al. Immunomodulatory Activity of Lactococcus lactis GCWB1176 in Cyclophosphamide-Induced Immunosuppression Model. Microorganisms 2020;8:1175.

51) Jacouton E, Michel ML, Torres-Maravilla E, Chain F, Langella P, Bermúdez-Humarán LG. Elucidating the immune-related mechanisms by which probiotic strain Lactobacillus casei BL23 displays anti-tumoral properties. Front Microbio/2019;9:3281.

52) Takagi A, Matsuzaki T, Sato M, Nomoto K, Morotomi M, Yokokura T. Enhancement of natural killer cytotoxicity delayed murine carcinogenesis by a probiotic microorganism. Carcinogenesis 2001:22:599-605.

53) Harata G, He F, Hiruta N, Kawase M, Kubota A, Hiramatsu M, et al. Intranasal administration of Lactobacillus rhamnosus $\mathrm{GG}$ protects mice from $\mathrm{H} 1 \mathrm{~N} 1$ influenza virus infection by regulating respiratory immune responses. Lett App/Microbio/2010;50:597-602.

54) Kim DH, Chung WC, Chun SH, Han JH, Song MJ, Lee KW. Enhancing the natural killer cell activity and anti-influenza effect of heat-treated Lactobacillus plantarum nF1-fortified yogurt in mice. J Dairy Sci2018:101:10675-84.

55) Nagai T, Makino S, Ikegami S, Itoh H, Yamada H. Effects of oral administration of yogurt fermented with Lactobacillus delbrueckii ssp. bulgaricus OLL1073R-1 and its exopolysaccharides against influenza virus infection in mice. Int Immunopharmaco/2011:11:2246-50.

56) Makino S, Sato A, Goto A, Nakamura M, Ogawa M, Chiba $Y$, et al. Enhanced natural killer cell activation by exopolysaccharides derived from yogurt fermented with Lactobacillus delbrueckii ssp. bulgaricus OLL1073R-1. J Dairy Sci2016:99:915-23.

57) Park JH, Ahn HJ, Kim SG, Chung CH. Dextran-like exopolysaccharide-producing Leuconostoc and Weissella from kimchi and its ingredients. Food SC Biotechno/2013;22:1047-53.

58) Ciszek-Lenda M, Nowak B, Sróttek M, Gamian A, Marcinkiewicz J. Immunoregulatory potential of exopolysaccharide from Lactobacillus rhamnosus KL37: Effects on the production of inflammatory mediators by mouse macrophages. Int J Exp Patho/2011:92:382-91. 